\title{
Tumor immune microenvironment in non-small cell lung cancer with EGFR mutation before and after EGFR-TKIs treatment
}

\author{
chao wang ${ }^{1}$, lihui $\operatorname{liu}^{1}$, sini li $^{1}$, hua bai ${ }^{1}$, and jie wang ${ }^{1}$ \\ ${ }^{1}$ Cancer Hospital Chinese Academy of Medical Sciences
}

February 21, 2021

\begin{abstract}
Lung cancer is the most common cancer and a leading cause of death from cancer in men and women in the world. Epidermal growth factor receptor tyrosine kinase inhibitors (EGFR-TKIs) are considered as the first-line treatment of EGFR mutated NSCLC. However, almost all patients eventually develop acquired resistance to EGFR-TKIs, with a median PFS of 9-14 months. With the development of immunotherapy, people realize that the interaction between tumor immune microenvironment (TIME) and tumor cells can also affect EGFR-TKIs treatment. TIME contains a variety of elements and previous researches of TIME in EGFR-TKIs therapy on NSCLC are decentralized. Here, we review the characteristics of TIME in NSCLC from EGFR-TKIs therapy and its role in TKIs resistance.
\end{abstract}

Tumor immune microenvironment in non-small cell lung cancer with EGFR mutation before and after EGFR-TKIs treatment

Chao Wang ${ }^{1,+}$, Lihui $\mathrm{Liu}^{1,+}$, Sini $\mathrm{Li}^{1}$, Hua Bai ${ }^{1,2^{*}}$

and Jie Wang ${ }^{1,2, *}$

${ }^{1}$ National Cancer Center/National Clinical Research Center for Cancer/Cancer Hospital, Chinese Academy of Medical Sciences and Peking Union Medical College, Beijing, 100021, China

${ }^{2}$ State Key Laboratory of Molecular Oncology, Department of Medical Oncology, National Cancer Center/National Clinical Research Center for Cancer/Cancer Hospital, Chinese Academy of Medical Sciences and Peking Union Medical College, Beijing, 100021, China

+ These authors contribute equally to this study

\section{* Address correspondence to:}

Jie Wang, M.D., Ph.D., State Key Laboratory of Molecular Oncology, Department of Medical Oncology, National Cancer Center/National Clinical Research Center for Cancer/Cancer Hospital, Chinese Academy of Medical Sciences \& Peking Union Medical College, Beijing, China, 100021, Beijing, China. zlhuxi@163.com; Tel: +86-13910704669

Hua Bai, M.D., Ph.D., State Key Laboratory of Molecular Oncology, Department of Medical Oncology, National Cancer Center/National Clinical Research Center for Cancer/Cancer Hospital, Chinese Academy of Medical Sciences \& Peking Union Medical College, Beijing, China, 100021, Beijing, China. huabaihb@sina.com; Tel: +86-13810095769

\section{Abstract}

Lung cancer is the most common cancer and a leading cause of death from cancer in men and women in the world. Epidermal growth factor receptor tyrosine kinase inhibitors (EGFR-TKIs) are considered as the 
first-line treatment of EGFR mutated NSCLC. However, almost all patients eventually develop acquired resistance to EGFR-TKIs, with a median PFS of 9-14 months. With the development of immunotherapy, people realize that the interaction between tumor immune microenvironment (TIME) and tumor cells can also affect EGFR-TKIs treatment. TIME contains a variety of elements and previous researches of TIME in EGFR-TKIs therapy on NSCLC are decentralized. Here, we review the characteristics of TIME in NSCLC from EGFR-TKIs therapy and its role in TKIs resistance.

\section{Key words}

EGFR mutation, NSCLC, EGFR-TKIs, tumor immune microenvironment

\section{Introduction}

Lung cancer is the most common cancer and a leading cause of death from cancer in men and women in the world with a 5-year survival rate about 19\%[1]. According to the global cancer statistics, the incidence and mortality of lung cancer in the male population ranked first place in the world's malignant tumor, and incidence in the female population ranked third place, mortality ranked second place[2]. In China, the incidence and mortality of lung cancer are the highest in the male population, and the incidence in the female is second place, and mortality is the first place[3].

Epidermal growth factor receptor (EGFR), also known as ERBB1 and HER1, is a transmembrane tyrosine kinase receptor (RTK), which is a member of the human epidermal receptor (HER) family and a crucial component of cell signal pathways[4]. Overexpression and mutation of EGFR can lead to activation of important signaling pathways, such as Ras-MAPK, PI3K-Akt, and STAT, increasing cell proliferation, angiogenesis, and metastasis[5]. About $40 \%$ to $80 \%$ of patients with non-small cell lung cancer (NSCLC) have EGFR mutation or overexpression[6]. Among them, EGFR mutations were found in 15\% of Caucasians and 30-50\% of Asian NSCLC patients[7-9]. Epidermal growth factor receptor tyrosine kinase inhibitors (EGFR-TKIs), which are classic small molecule inhibitors can inhibit the EGFR tyrosine kinase domain reversibly through competitive binding with ATP[10]. At present, EGFR-TKIs commonly used in the clinic include gefitinib and erlotinib of the first generation, afatinib and dacomitinib of the second generation, and osimertinib of the third generation. Several clinical trials have shown that EGFR-TKIs can prolong the survival time of patients with tumors harboring EGFR-activating mutations[11-33]. The main clinical trials are shown in Table.

However, patients initially responding to EGFR-TKIs invariably develop resistance and the median progression free survival was about 10 months[11, 16, 23, 30]. Resistance to EGFR-TKIs is inevitable due to various mechanisms, such as the secondary mutation known as T790M(50\%)[34]; MET amplification(5\%), HER-2 amplification(8\%), PI3K mutation(5\%), histologic transformation(14\%)[35, 36]; new mutations like EFGR-C797S mutation, EGFR-L792H mutation and EGFR-G796R[37-39]. Previous studies focused too much on drug resistance caused by tumor cells, and few on tumor immune microenvironment. Therefore, it is imperative to study the mechanism of tumor immune microenvironment in tumor drug resistance. The tumor immune microenvironment (TIME) contains numerous cell types in addition to cancer cells, which include bone marrow-derived inflammatory cells, lymphocytes, blood vessels, fibroblastic cells, and the extracellular matrix composed of collagen and proteoglycans $[40,41]$. Next, this review will describe the TIME of NSCLC with EGFR mutation in five aspects: tumor extracellular matrix; Cancer-associated fibroblasts; Tumor vasculature; tumor infiltrating immune cells; Cytokines secreted by tumor and immune cells.

\section{Extracellular matrix}

The extracellular matrix (ECM) is the non-cellular component present within all tissues and organs, and provides not only essential physical scaffolding for the cellular constituents but also initiates crucial biochemical and biomechanical cues that are required for tissue morphogenesis, differentiation, and homeostasis[42]. The interaction between NSCLC tumor cells with EGFR mutation and the ECM is crucial for tumor development (Figure 1A). EGFR mutation can increase twist, snail, and other gene expression in the process of tumor development, which induced epithelial mesenchymal transition (EMT) and promoted tumor cell 
invasion and metastasis, EGFR-TKIs can inhibit EMT and prevent tumor cell invasion and metastasis[43, 44]. The activation of EGFR in tumor cells can also increase the activity of matrix metalloproteinase-9 (MMP-9), which can promote the destruction of the ECM barrier and the invasiveness of tumor cells[45, 46]. In recent years, many studies have found that ECM is related to EGFR-TKIs resistance. The ECM of tumor cells with EGFR-TKIs resistance highly expresses integrin- $\beta 1$, which is a collagen receptor, and produces a large amount of collagen around the tumor cells. The sensitive cell lines showed EGFR-TKIs resistance after co-cultured with Integrin $\beta-1$ which was extracted from drug-resistant cell lines, and inhibition of integrin $\beta-1$ expression can reverse EGFR-TKIs resistance[47].

\section{Cancer-associated fibroblasts}

Cancer-associated fibroblasts are one of the important components of the tumor microenvironment, which are activated by growth factors, direct intercellular communication, adhesion molecules, and other factors. Different from normal fibroblasts, CAFs are perpetually activated, do not return to normal phenotype and apoptosis, also promote tumor progression[48]. CAFs play an important role in the malignant progression of cancer by releasing growth factors and cytokines which stimulate angiogenesis, cell proliferation, invasion, and metastasis[48]. The function of CAFs in EGFR-TKIs sensitive lung cancer is different from that in EGFR-TKIs resistant lung cancer (Figure 1B). In vitro and in vivo experiments showed that CAFs in EGFR-TKIs resistant lung cancer increased the expression and phosphorylation of ANXA2 by secretion of growth factors HGF and IGF-1 and by activation of the corresponding receptors c-met and IGF-1R, which induced EMT of tumor cells and promoted EGFR-TKIs resistance[49]. In addition, CD200-positive CAFs in tumor tissues can augment the sensitivity of EGFR mutant tumor cells to EGFR TKI[50]. Another study found that podoplanin-positive CAFs promoted tumor cells to EGFR-TKIs resistance and inhibition of the expression of podoplanin in CAFs can reverse the drug resistance[51]. A recent study found that mesenchymal cells isolated from EGFR mutant lung cancer can differentiate into CAFs which can promote tumor invasion and metastasis[52].

\section{Tumor vasculature}

Tumor vasculature is another important component of the tumor microenvironment. Tumor vasculature arises from two different biological processes: angiogenesis consisting of the formation of new blood vessels from pre-existing vessels and vasculogenesis consisting of the formation of new blood vessels by recruitment of circulating endothelial progenitor cells[53]. Hypoxia inducible factors (HIFs) are one of the main signals regulating the process of angiogenesis which induce transcription of genes responsible for activation of angiogenesis[54]. Another important regulator is the vascular endothelial growth factor (VEGF) and its receptor (VEGFR), which can stimulate angiogenesis[55]. Tumor vasculature in EGFR mutant lung cancer is different from that in EGFR wild type lung cancer (Figure 1C). It was found that the vascular-poor area in lung adenocarcinoma with EGFR mutation is less than the tumor without EGFR mutation[56]. Another study found that tumors with mutations in exon 20 and 21 of EGFR exhibited a high level expression of VEGFR, while those with mutations in exon 19 of EGFR exhibited a low level expression of VEGFR[57]. For EGFR-TKIs resistant non-small cell lung cancer, heat shock protein 90 (Hsp90) inhibitors can overcome HGF-triggered resistance to EGFR-TKIs by reducing EGFR protein expression and tumor angiogenesis[58]. Another study found that Met activation by HGF stimulated the production of vascular endothelial growth factor (VEGF) and facilitated angiogenesis, which indicated that HGF induced EGFR-TKIs resistance and angiogenesis. Triple inhibition of EGFR, Met, and angiogenesis was useful for controlling the progression of EGFR-mutant lung cancer with HGF-triggered EGFR-TKIs resistance[59]. An in vivo and in vitro experiment on EGFR-TKIs combined with chemotherapy in the treatment of EGFR mutant lung cancer found that EGFR-TKIs combined with chemotherapy can inhibit tumor progression and angiogenesis by down regulating c-MYC and HIF- $\alpha$ pathways[60].

\section{Tumor infiltrating immune cells}

At present, the majority of research on tumor immune microenvironment is tumor infiltrating immune cells, and almost All immune cell types can be found in the tumor microenvironment, including tumor associated 
macrophages (TAM), dendritic cells (DC), natural killer cells (NK), B lymphocytes (B cell), T lymphocytes (T cell), marrow-derived suppressor cells (MDSC), neutrophils, etc.[61]. The immune cells play an important role in shaping the TIME of EGFR mutant lung cancer by secreting cytokines and activating signal pathways (Figure 2).

\section{Tumor associated macrophages}

Macrophage originates from progenitors in the bone marrow and enters the peripheral blood. During homeostasis and inflammation, they migrate into tissues and differentiate into macrophage following exposure to local growth factors, proinflammatory cytokines, and microbial products. The function of macrophages in the tumor is multiple[62]. As for tumor associated macrophages (TAM), studies have found that the number of CD68 positive and CD204 positive TAM in EGFR mutant NSCLC tumor tissues is less than that of EGFR wild type, and the prognosis is better[63]. Moreover, EGFR mutated lung cancer with high infiltrating CD204 positive TAM had high aggressiveness and poor prognosis[64]. Another study found that EGFR-TKIs resistant lung cancer was correlated to tumor infiltrating CD68 positive TAM and S100A9 positive MDSC, which resulted in resistance through the NF- $x \mathrm{~B}$ pathway[65]. Two major macrophage subpopulations with different functions include classically activated or inflammatory (M1) and alternatively activated or antiinflammatory (M2) macrophages have been recognized. M1 macrophage has robust anti-tumoral activity whereas M2 macrophage promotes tumor formation and progression[66].CD68 positive and CD204 positive TAM is M2 type macrophage. It was found that the level of M2 type macrophage in EGFR-TKIs resistant lung cancer was higher than that in EGFR-TKI sensitive lung cancer[67]. Therefore, it can be inferred that EGFR-TKIs resistance is related to M2 type TAM, and reducing M2 type TAM may reverse EGFR-TKIs resistance.

\section{Dendritic cells}

Dendritic cells (DC) are unique immune cells linking innate and adaptive immune responses. They are considered as the most effective antigen presenting cells, which play an important role in the process of tumor antigen recognition and presentation[68]. It was found that the level of major histocompatibility complex class II (MHC II) positive DC in EGFR-TKIs sensitive tumor was higher than that in EGFR-TKIs resistant tumor[69]. Another study found that lung cancer with EGFR mutation inhibited the maturation of DC and induced the production of anergic DC to repress antitumor immunity through exosomes[70]. Analysis of the NSCLC transcriptomic dataset revealed selective overexpression of CD47 in patients with EGFR mutation. EGFR-TKIs significantly reduced CD47 expression on the surface of pre-apoptotic cells, favoring more efficient engulfment of cancer cells by DC. CD47 expression became up-regulated following EGFR-TKIs resistance development, and blocking of this protein by a specific monoclonal antibody increased the clearance of EGFR-TKI resistant cells by phagocytes[71]. Therefore, EGFR-TKIs resistance is associated with decreasing of DC and malfunction of DC.

\section{Natural killer cells}

Natural killer cells (NK) are lymphocytes of the innate immune system that monitor cell surfaces of autologous cells for an aberrant expression of major histocompatibility complex class I (MHC I) molecules and cell stress markers, which play an important role in antitumor immune responses[72]. The study found that patients with high expression of NK cells had a greater OS and PFS and NK cells increased after EGFR-TKIs treatment[73]. For EGFR-TKIs resistant lung cancer, up regulating ICAM1 can induce drug resistance, and NK92-CD16 cells combined with the EGFR antibody could reverse the drug resistance[74]. Another study found that gefitinib greatly enhanced NK cells cytotoxicity to lung cancer cells with EGFR L858R+T790M resistance mutation. Gefitinib could block the immune escape by up-regulating the expression of NKG2D ligands ULBP1, ULBP2, or MICA on tumor cells and NKG2D on NK cells in the co-culture system[75]. A combination of EGFR-TKIs and NK cells adoptive immunotherapy may represent a potentially effective strategy for EGFR-TKIs resistant lung cancer.

\section{Myeloid-derived suppressor cells}


Myeloid-derived suppressor cells (MDSC) are derived from bone marrow and can support tumor progression by promoting tumor cell survival, angiogenesis, invasion of healthy tissue by tumor cells, and metastases[76]. MDSC consist of two large groups of cells termed granulocytic or polymorphonuclear (PMN-MDSC), which are phenotypically and morphologically similar to neutrophils; and monocytic (M-MDSC)-phenotypically and morphologically similar to monocytes[77]. It was found that a high percentage of MDSC in EGFR mutant lung cancer was correlated with poor prognosis and reducing MDSC can improve the prognosis[78]. In addition, S100A9 positive MDSC counts in EGFR-TKIs resistant lung cancer was higher than healthy donors. Further study found that this kind of MDSC could be transformed into M2 type TAM by activating the RELB gene, thus promoting the proliferation and metastasis of tumors and resulting in EGFR-TKIs resistance[65]. At present, there are few studies on the mechanism of MDSC that participated in EGFR-TKIs resistance. Whether MDSC inhibition can reverse EGFR-TKIs resistance needs further study.

\section{Neutrophils}

Neutrophils which are the largest number of immune cells in humans have always been considered as uncomplicated front-line troopers of the innate immune system. Recently, studies have found that neutrophils are associated with anti-tumor immune response[79]. Several studies have found that a low neutrophil-tolymphocyte ratio was a good prognostic factor in EGFR mutant NSCLC patients receiving EGFR-TKIs treatment[80-82]. Another study found that intratumoral neutrophil density was lower in EGFR mutant NSCLC comparing with non- EGFR mutant NSCLC[83]. At present, there are few studies on the relationship between neutrophils and EGFR-TKIs resistance mechanism. Whether neutrophils are related to EGFR-TKIs resistance needs further study.

\section{B lymphocytes}

B lymphocytes (B cells) are an important part of the human adaptive immune response and humoral immune response. Studies have found that B cells play an important role in anti-tumor immune response[84]. According to the analysis of the TCGA database, tumor infiltrating B cells (TIB) abundance is significantly higher in the NSCLC with EGFR mutation[85]. Studies have found that B cells usually existed in a tissue called tertiary lymphoid structure (TLS), and TLS was associated with a good prognosis[86]. The main function of B cells is humoral immune response, in lung tissue, B cells differentiate into plasma cells, which produce specific antibodies and recognize tumor associated antigens[86, 87]. In addition, activated TIB can activate tumor infiltrating T cells (TIT) through presenting tumor antigen to TIT and activating the anti-tumor effect of TIT[88]. However, regulatory B cell (Breg), a subtype of B cells, can inhibit immunity and promote tumor proliferation and metastasis[89]. It has been found that Breg can weaken the response of $\mathrm{T}$ cells and NK cells and facilitate the immune suppressive activity of regulatory T cells (Treg) by up-regulating immune

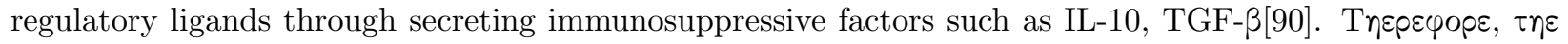

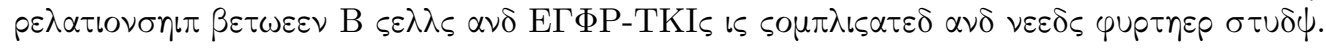

\section{$\mathrm{T} \lambda \psi \mu \pi \eta \circ \varsigma \psi \tau \varepsilon \varsigma$}

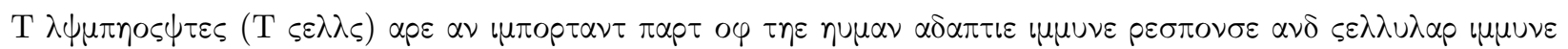

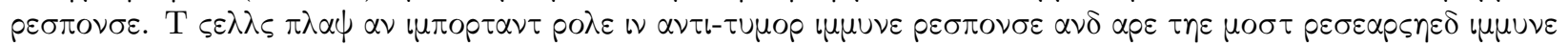

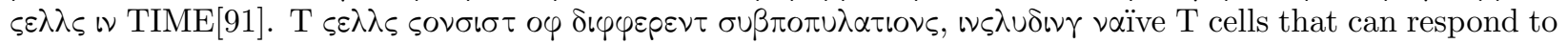
new antigens, memory $\mathrm{T}$ cells that are activated from previous antigens and maintain long-term immunity, and regulatory $\mathrm{T}$ cells that regulate immune response[91]. It was found that the percentage of TIT in EGFR mutant NSCLC was lower than that in NSCLC without EGFR mutation, and a low percentage of TIT predicted poor prognosis[92]. Another study found that the number of CD8+CD39+T cells in EGFR mutant NSCLC patients was less than that in EGFR wild-type NSCLC patients. The study suggested that CD39+T cells were related to the good effect of the immune checkpoint inhibitor (ICI), which partly explained the poor effect of EGFR mutated NSCLC on ICI[93]. Moreover, it was found that the number of CD8+ tumor infiltrating $\mathrm{T}$ cells in EGFR mutant NSCLC was less than that in EGFR wild type NSCLC[94], and the proportion of PD-L1 + or PD-1 +, CD8 + T cells in CD8 + T cells were also less comparing with non-EGFR mutant NSCLC $[95,96]$. This was also confirmed by an animal experiment on genetically engineered mice 
with EGFR mutation. The study found that the number of CD8+ TIT in mice with EGFR mutation was less than that with EGFR wild type and other driving gene mutations[97]. T cell immunoglobulin and mucin domain containing protein 3 (TIM3) is a member of the TIM family. Studies have found that the number of TIM3+T cells in the EGFR mutant NSCLC tumor is less than that in EGFR wild type tumor, and T cells with TIM3 positive consisted of CD8+T cells, CD4+T cells, and NKT cells[98].

On the comparison of before and after EGFR-TKIs treatment, the study found that the total T cells, CD4+T cells, and CD8+T cells of patients with EGFR mutation had no significant changes before and after EGFRTKI treatment, but the ratio of CD4+/CD8+T cells increased, and the high ratio of CD4+/CD8+T cells was associated with poor prognosis[73]. Studies have found that $\mathrm{T}$ cell apoptosis was caused by EGFR mutation which increased the expression of PD-L1 through the p-ERK1/2/p-c-jun pathway. EGFR-TKIs prevented $\mathrm{T}$ cell apoptosis and inhibit tumor proliferation by decreasing the expression of PD-L1 through inhibiting the EGFR pathway[99]. Another study found that the number of Treg in EGFR mutant NSCLC was less than that in non-EGFR mutant NSCLC, because The EGFR signal activated cJun/cJun N-terminal kinase and reduced interferon regulatory factor-1; the former increased CCL22, which recruits CD4+ regulatory $\mathrm{T}$ cells, and the latter decreased CXCL10 and CCL5, which induce CD8+ T cell infiltration. EGFR-TKIs can reverse this phenomenon by inhibiting EGFR signaling pathway[100]. The anti-tumor response of $\mathrm{T}$ cells is recognition of the tumor antigen presented by MHC-I. Studies have found that EGFR mutation decreased the expression of MHC-I through the MEK-ERK pathway. EGFR-TKIs increased the expression of MHC-I by inhibiting the EGFR pathway, and recruited $\mathrm{T}$ cells to the tumor. Therefore, the number of CD8+T cells in the tumor after EGFR-TKIs treatment is more than that before treatment[101].

Someone used a classification based on the PD-L1 and CD8-positive tumor infiltrating lymphocytes (TIL) statuses. The outcomes of patients with a negative PD-L1 expression and a high CD8-positive TIL count were significantly better than those with other classifications. In patients with positive PD-L1 and high CD8-positive TIL, the rate of EGFR mutation was significantly lower than that in non-EGFR mutation[102]. Moreover, for positive PD-L1 and high CD8+TIL NSCLC with EGFR mutation, the prognosis of EGFRTKIs is poor, but this type of NSCLC is likely to respond to ICI[103, 104]. A study found that the proportion of PD-L1 positive T cells in peripheral blood of patients with EGFR mutation is less than that in non-EGFR mutation patients. However, the proportion of PD-L1+T cells in peripheral blood of patients with EGFR mutation is significantly increased after the EGFR-TKIs treatment. Moreover, PD-L1+T cells are positively correlated with the poor response of EGFR-TKIs[105]. For uncommon EGFR-mutant tumors, including G719X, L861Q, S768I, and Ex20 ins, the PD-L1 expression in tumor cells was higher than that in common EGFR mutant tumors. Moreover, the proportion of CD8+TIL in uncommon EGFR-mutant tumors was more than that in common EGFR mutant tumors. Patients with high expression of PD-L1 and abundant CD8+TIL exhibited a poor response to EGFR-TKIs, but the better response to ICI[106]. There are many studies about T cells with EGFR mutation and EGFR-TKIs resistance, and the mechanisms of EGFR-TKIs resistance are diverse. Therefore, the theapeutic strategy on $\mathrm{T}$ cells is one of the research directions for reversing EGFR-TKIs resistance.

\section{Cytokines secreted by tumor and immune cells}

Cytokines are small molecular proteins with extensive biological activities synthesized and secreted by immune cells and non-immune cells through stimulation, including interleukin, interferon, tumor necrosis factor superfamily, colony stimulating factor, chemokines, growth factors, etc.[107], which play an important role in tumor inhibition, proliferation and metastasis (Figure 3). Studies have found that in EGFR mutant lung cancer, alveolar macrophages downregulated surface expression of MHC-II and costimulatory molecules; increased production of CXCL1, CXCL2, IL1 receptor antagonist; and increased phagocytosis. EGFR-TKIs can decrease alveolar macrophages in EGFR mutant lung cancer[108]. It has been found that EGFR-TKIs can induce PD-L1 protein degradation in NSCLC cells with EGFR mutation through the GSK3 $\beta$ pathway and ubiquitin protease pathway, which contributed to $T$ cell activation[109]. In addition, EGFR mutation can up regulate amphiregulin (AREG) and AREG maintained the Treg cell suppressive function via the EGFR/GSK-3 $3 /$ Foxp3 axis, furthermore, inhibition of EGFR by EGFR-TKIs restored the activity of 
GSK-3 $\beta$ and attenuated Treg cell function[110].

As for EGFR-TKIS resistance, it was found that Axl kinase was overexpression in EGFR-TKI resistant NSCLC, which was positively correlated with the expression of genes encoding immune checkpoint molecules (CD274, CTLA4), chemokine receptors (CXCR4, CXCR6), or chemokines (CXCL16). These chemokines can induce tumor invasion and metastasis. Inhibition of Axl kinase activity can reduce the expression of these chemokines[111]. In addition, studies have found that overexpression of hepatocyte growth factor (HGF) induces EMT through the HGF-MET pathway, resulting in EGFR-TKIs resistance[112-120]. MiR-1-3p and miR-206 can reverse HGF-induced EGFR-TKIs resistant lung cancer through inhibition of c-Met signaling and EMT[121]. Overexpression of PD-L1 is one of the mechanisms of EGFR-TKIs primary resistance. Studies have found that PD-L1 led to EGFR-TKIs primary resistance by inducing EMT through the TGF$\beta / \mathrm{Smad} 3$ pathway. Inhibition of the TGF- $\beta / \mathrm{Smad} 3$ pathway can reverse EGFR-TKIs resistance[122-124]. Moreover, the activation of the TGF- $\beta /$ Smad2 pathway can induce EMT and EGFR-TKIs resistance by increasing the expression of CXCR $4[124,125]$. The study also found that TGF- $\beta$ can induce EMT and

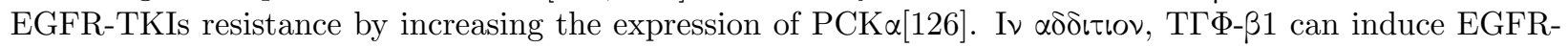
TKIs resistance by activating the Akt-ERK pathway, increasing the expression of MIG6, and decreasing the expression of PTEN[127, 128].

It was found that overexpression of IL-6 in EGFR-mutant NSCLC was correlated with EGFR-TKIs resistance[129]. In addition, the activation of the adrenergic $\beta 2$ receptor can induce EGFR-TKIs resistance by increasing the expression of IL-6[130]. For the detection of serum cytokines in NSCLC with EGFR mutation, the study found that patients with high levels of IL-6, VEGF, and HGF in serum had a poor response to EGFR-TKIs treatment. Dynamic change of these cytokines in blood during TKIs treatment can predict the efficacy of EGFR-TKIs[131, 132]. Studies have found that RNF25 promoted EGFR-TKIs resistance in EGFR-mutant NSCLC cells by inducing ERK reactivation through the expression of IL6 via the NK- $\varkappa \mathrm{B}$ signal pathway, and inhibition of RNF25 or NF- $\chi \mathrm{B}$ and ERK pathways can reverse EGFR-TKIs resistance[133]. In addition, studies have found that overexpression of miR-762 which was induced by IL6, promoted EGFR-TKIs resistance in NSCLC through posttranscriptional repression of active BCR related protein (ABR) [134]. Not only IL-6 can induce EGFR-TKIs resistance, but also IL-8 can induce EGFR-TKIs resistance by EMT through activation the MAPK singnal pathway[135].

Integrin linked kinase (ILK) regulates the interaction between tumor cells and the extracellular environment, activates signal pathway, promotes cell proliferation, migration and EMT. SHP2 is crucial for the activation of the receptor tyrosine kinase signal pathway. Studies have found that ILK and SHP are highly expressed in EGFR-TKIs resistant NSCLC[136]. Other studies have found that secreted phosphoprotein 1 (SPP1) was significantly increased in EGFR-TKIs resistant lung cancer cells, and inhibition of SPP1 increased sensitivity of lung cancer cells to EGFR-TKIs and decrease the ability of invasion[137]. Overexpression of type 1 insulin-like growth factor receptor (IGF1R) is associated with EGFR-TKIs resistance. Studies have found that overexpression of IGF1R can promote EGFR-TKIs resistance by inducing EMT of tumor cells, and inhibition of IGF1R can reverse EMT of tumor cells and sensitivity to EGFR-TKIs[138]. CXCR7, an atypical G protein-coupled receptor, can promote EGFR-TKIs resistance by EMT of tumor cells through activation of MAPK-ERK pathway via $\beta$-arrestin[139]. There are many studies on the relationship between cytokines and EGFR mutation and EGFR-TKIs resistance, involving complex and diverse signaling pathways, which can be classified as one point, namely tumor EMT. Therefore, inhibitors targeting multiple pathways of EMT may be one of the research directions for reversing EGFR-TKIs resistance.

\section{Conclusion}

In conclusion, the tumor immune microenvironment of EGFR mutated NSCLC is different from that of non-mutated NSCLC, which is one of the reasons why EGFR mutated NSCLC is a poor response to ICI. The tumor immune microenvironment of EGFR mutated NSCLC also changes during the treatment of EGFR-TKIs. The tumor immune microenvironment of EGFR-TKIs resistance can be summarized into three points:1. Comparing with EGFR-TKIs sensitive tumor, there are more immunosuppressive cells and fewer immune activated cells in EGFR-TKIs resistant tumor and the tumor microenvironment is an immunosup- 
pressive state;2. Tumor cells and immunosuppressive cells secrete many immune negative regulatory factors, inhibit the recognition and presentation of tumor antigen and the antitumor effect of immune cells, resulting in immune escape;3.EGFR-TKIs resistant tumor appears EMT. The above three points interact with each other to form a signal regulatory network, which together leads to EGFR-TKIs resistance. Inhibiting one of them can not fundamentally reverse the EGFR-TKIs resistance. Therefore, future research on reversing EGFR-TKIs resistance needs to invent pan targeted drugs that inhibit the key points of the signal regulatory network, change immune cell infiltration, change immune regulatory factors and reverse EMT, and finally reverse EGFR TKIs resistance.

\section{Funding}

This study was supported by the National Natural Sciences Foundation Key Program [81630071].

\section{Disclosure}

All authors have completed the ICMJE uniform disclosure form at www.icmje.org/coi_disclosure.pdf. We all declare the following: we haven't received support from any organisation for the submitted work; we have no financial relationships with any organisations that might have an interest in the submitted work in the previous three years; and we have no other relationships or activities that could appear to have influenced the submitted work.

Table. Clinical trials of EGFR-TKI in EGFR mutated NSCLC

\begin{tabular}{|c|c|c|c|c|c|}
\hline Authors & Numbers of patients & Groups & mOS(month) & $\mathrm{P}$ value & $\mathrm{mPFS}$ \\
\hline \multirow{2}{*}{ MokTS [11] } & 261 & Gefitinib & & & 10 \\
\hline & & Carboplatin + paclitaxel & & & 7 \\
\hline \multirow[t]{2}{*}{ Maemondo M [12] } & 230 & Gefitinib & 30.5 & $\mathrm{P}_{j} 0.001$ & 10.8 \\
\hline & & Carboplatin + paclitaxel & 23.6 & & 5.4 \\
\hline \multirow[t]{2}{*}{ Sun JM [14] } & 33 & Gefitinib & & & 15.7 \\
\hline & & Pemetrexed & & & 2.9 \\
\hline \multirow[t]{2}{*}{ Mitsudomi T [15] } & 172 & Gefitinib & & & 9.2 \\
\hline & & Docetaxel & & & 6.3 \\
\hline \multirow[t]{2}{*}{ Wu YL [16] } & 217 & Erlotinib & 26.3 & $\mathrm{P}=0.607$ & 11 \\
\hline & & Gemcitabine + cisplatin & 25.5 & & 5.5 \\
\hline \multirow[t]{2}{*}{ Zhou C $[17,18]$} & 154 & Erlotinib & 22.8 & $\mathrm{P}=0.2663$ & 13.1 \\
\hline & & Standard chemotherapy & 27.2 & & 4.6 \\
\hline \multirow[t]{2}{*}{ Rosell R [21] } & 174 & Erlotinib & 19.3 & $\mathrm{P}=0.87$ & 9.7 \\
\hline & & Standard chemotherapy & 19.5 & & 5.2 \\
\hline \multirow[t]{2}{*}{ Wu YL $[23]$} & 364 & Afatinib & & & 11 \\
\hline & & Cisplatin + gemcitabine & & & 5.6 \\
\hline \multirow[t]{2}{*}{ Sequist LV [24] } & 345 & Afatinib & & & 11.1 \\
\hline & & Cisplatin + pemetrexed & & & 6.9 \\
\hline \multirow[t]{2}{*}{$\begin{array}{l}\mathrm{Wu} \text { YL } \\
\mathrm{P}=0.2224\end{array}$} & Mok TS $[26,27]$ & 452 & Dacomitinib & 34.1 & $\mathrm{P}=0$. \\
\hline & & Gefitinib & 26.8 & & 9.2 \\
\hline \multirow[t]{2}{*}{$\begin{array}{l}\text { Soria JC } \\
\mathrm{P}=0.24\end{array}$} & Ramalingam SS [28, 29] & 556 & Osimertinib & 38.6 & $\mathrm{P}=0$ \\
\hline & & Gefitinib & 31.8 & & 10.2 \\
\hline \multirow[t]{2}{*}{ Mok TS [30] } & 419 & Osimertinib & & & 10.1 \\
\hline & & Pemetrexed + Carboplatin / cisplatin & & & 4.4 \\
\hline
\end{tabular}

Abbreviations: mOS, median overall survival; $\mathrm{mPFs}$, median progression free survival; ORR, objective response rate 


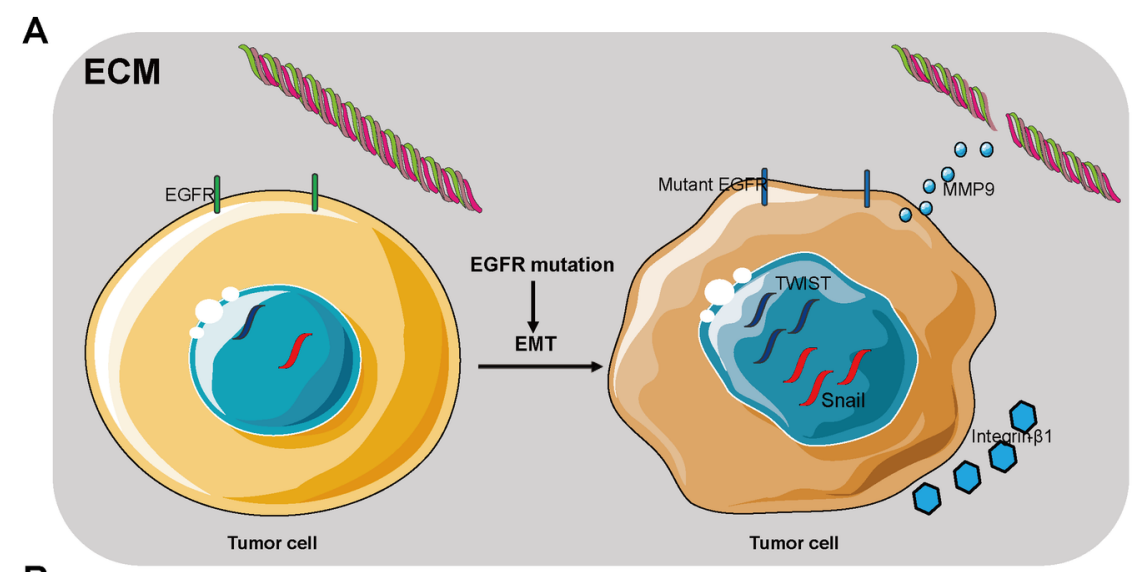

B

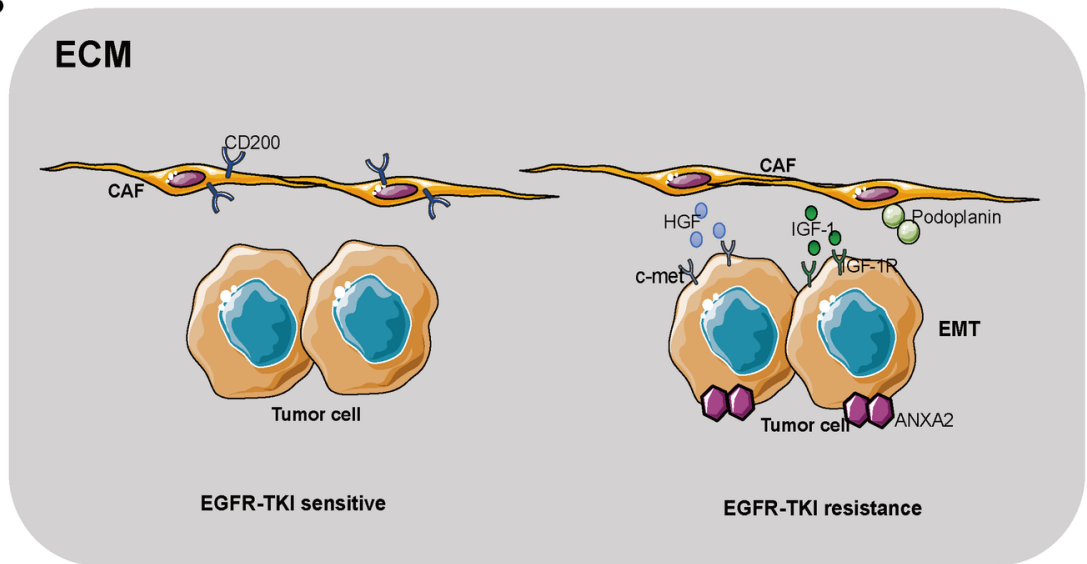

C

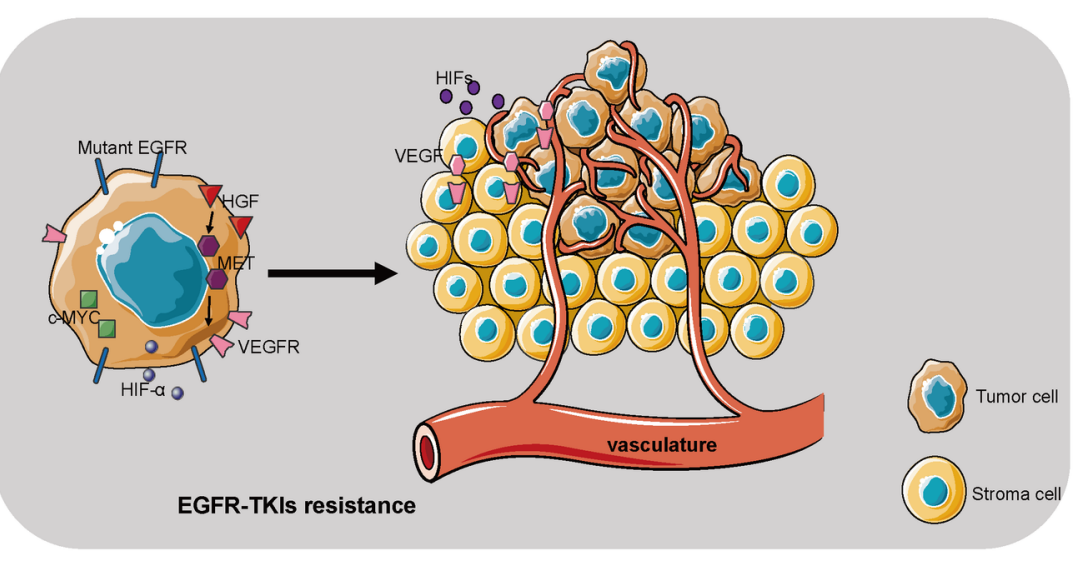

Figure 1. The ECM, CAFs and Vasculature in TIME of EGFR mutant lung cancer.

A. The ECM in TIME of EGFR mutant lung cancer, EGFR mutant lung cancer cell overexpresses twist and snail, which induces EMT. EGFR mutant lung cancer cell also overexpresses MM9, which destructs the ECM barrier. EGFR-TKIs resistant lung cancer cell highly expresses integrin- $\beta 1$. B. The CAFs in TIME of EGFR mutant lung cancer. In EGFR-TKIs sensitive lung cancer, the CAFs highly expresses CD200. In EGFR-TKIs resistant lung cancer, the CAFs highly expresses c-met and IGF-1, which induces tumor cell overexpresses ANX2 and EMT. The CAFs in TIME of EGFR-TKIs resistant lung cancer also expresses podoplanin. C. Vasculature in TIME of EGFR-TKIs resistant lung cancer. The expression of HGF promotes the activation of MET, which stimulates the production of VEGFR. The activation of c-MYC and 
overexpression of HIF- $\alpha$ also induces EGFR-TKIs resistance.

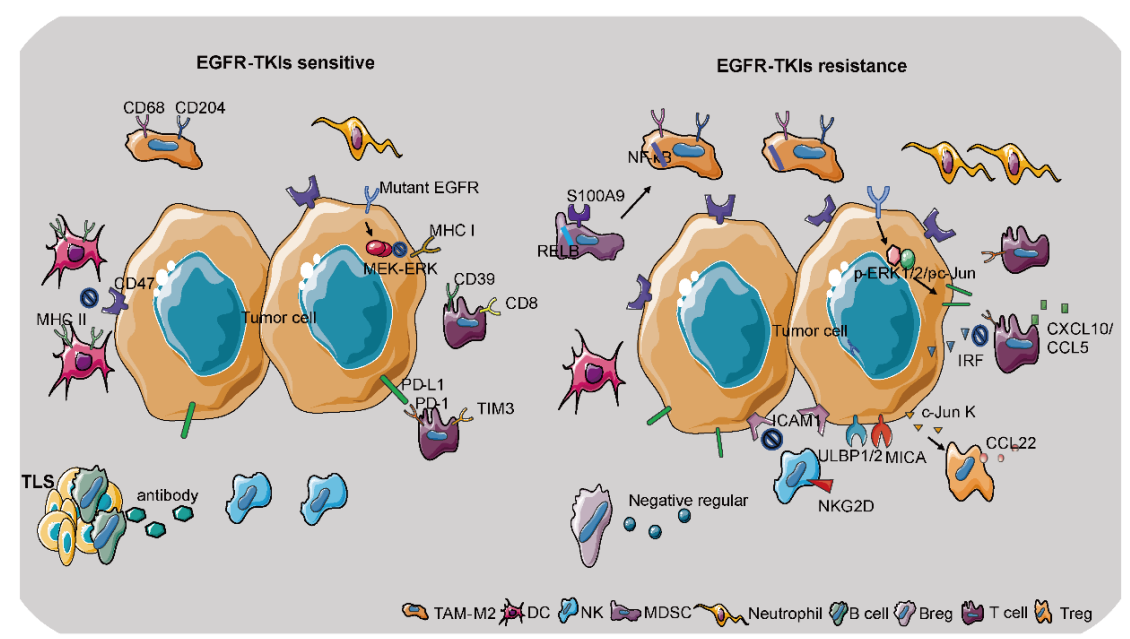

Figure 2. Immune cells in TIME of EGFR mutant lung cancer.

The ratio of neutrophil, MDSC, CD68+ and CD204+ TAM(M2) in EGFR-TKIs sensitive lung cancer is less than that in EGFR-TKIs resistant lung cancer. However, the number of MHC II+DC and NK in EGFR-TKIs sensitive lung cancer is more than that in EGFR-TKIs resistant lung cancer. S100A9+MDSC transforms into M2 type TAM by activating RELB gene, and TAM(M2) induces EGFR-TKIs resistance through the NF- $x \mathrm{~B}$ pathway. The EGFR-TKIs resistant lung cancer cell expresses CD47 which blocks the phagocytosis and antigen presentation of DC. Up regulating the expression of ULBP1,2, MICA on tumor cell and NKG2D on NK can promote NK cytotoxicity to tumor cell. B cell exists in the TLS which is associated with a good prognosis. B cell also differentiates into plasma cell and produces specific antibodies and recognizes tumor associated antigens. Breg can weaken the response of T cells and NK cells and facilitate the immune suppressive activity of regulatory $\mathrm{T}$ cells (Treg) by secreting immunosuppressive factors. The number of $\mathrm{T}$ cell like CD39+, CD8+ or PD-1+, TIM3+ T cell in EGFR mutant lung cancer is less than that in EGFR wild type lung cancer. T cell apoptosis was caused by EGFR mutation which increased the expression of PD-L1 through the p-ERK1/2/p-c-jun pathway. The number of Treg in EGFR mutant NSCLC was less than that in non-EGFR mutant NSCLC. The EGFR signal activates cJun/cJun N-terminal kinase and reduces interferon regulatory factor-1; the former increases CCL22, which recruits CD4+ regulatory $\mathrm{T}$ cells, and the latter decreases CXCL10 and CCL5, which induce CD8+ T cell infiltration. EGFR mutation also decreases the expression of MHC-I through the MEK-ERK pathway. 


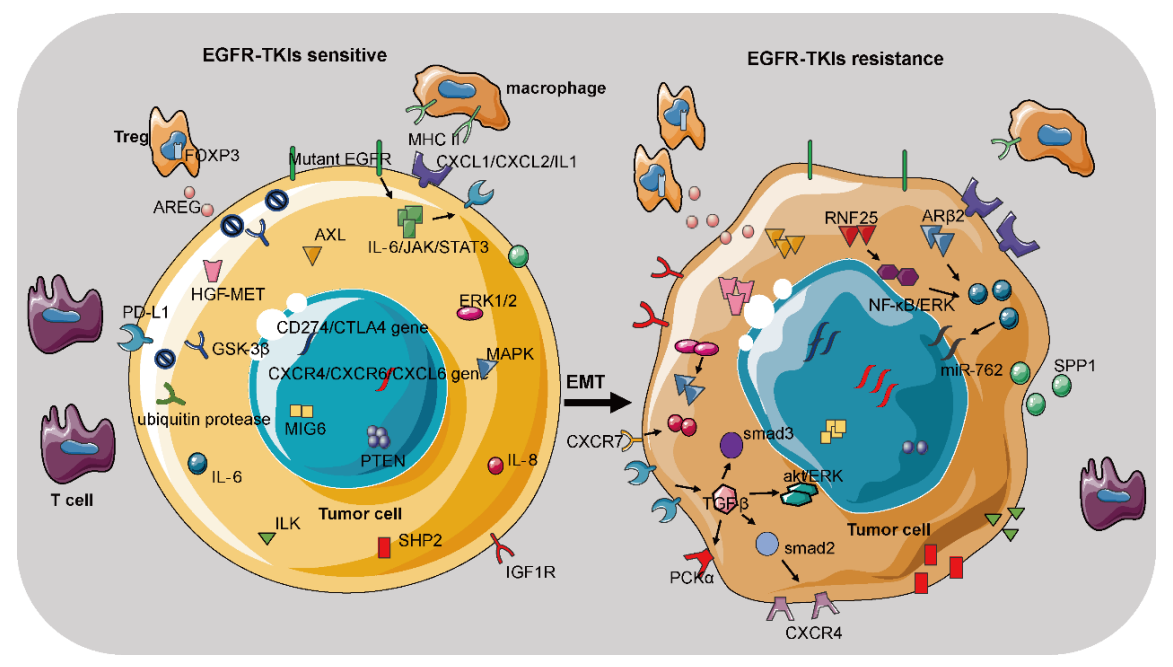

Figure 3. Cytokines in TIME of EGFR mutant lung cancer.

EGFR-TKIs can induce PD-L1 protein degradation through the GSK3 $\beta$ pathway and ubiquitin protease pathway, which contributes to $\mathrm{T}$ cell activation. EGFR mutation can up regulate amphiregulin (AREG) and AREG maintains the Treg cell suppressive function via the EGFR/GSK-3 $\beta$ /Foxp3 axis. Axl kinase, genes encoding immune checkpoint molecules (CD274, CTLA4), chemokine receptors (CXCR4, CXCR6), or chemokines (CXCL16) are overexpression in EGFR-TKI resistant NSCLC. Overexpression of hepatocyte growth factor (HGF) induces EMT through the HGF-MET pathway, resulting in EGFR-TKIs resistance. PD-L1 induces EMT through the TGF- $\beta /$ Smad3 pathway. Activation of the TGF- $\beta /$ Smad2 pathway can also induce EMT by increasing the expression of CXCR4. Furthermore, TGF- $\beta$ can induce EMT and EGFRTKIs resistance by increasing the expression of $\mathrm{PCK} \alpha$, activating the Akt-ERK pathway, increasing the expression of MIG6, and decreasing the expression of PTEN. Adrenergic $\beta 2$ receptor can induce EGFRTKIs resistance by increasing the expression of IL-6. RNF25 promoted EGFR-TKIs resistance by inducing ERK reactivation through the expression of IL6 via the NK- $x$ B signal pathway. ILK, SHP, SPP1, IGF1R are highly expressed in EGFR-TKIs resistant NSCLC. CXCR7 can promote EGFR-TKIs resistance by EMT of tumor cells through activation of MAPK-ERK pathway via $\beta$-arrestin.

\section{References}

1. Siegel RL, Miller KD, Jemal A. Cancer statistics, 2020. CA Cancer J Clin. 2020;70(1). doi: 10.3322/caac.21590. PubMed PMID: 31912902.

2. Bray F, Ferlay J, Soerjomataram I, Siegel RL, Torre LA, Jemal A. Global cancer statistics 2018: GLOBOCAN estimates of incidence and mortality worldwide for 36 cancers in 185 countries. CA Cancer J Clin. 2018;68(6):394-424. doi: 10.3322/caac.21492. PubMed PMID: 30207593.

3. Chen W, Zheng R, Baade PD, Zhang S, Zeng H, Bray F, et al. Cancer statistics in China, 2015. CA Cancer J Clin. 2016;66(2):115-32. doi: 10.3322/caac.21338. PubMed PMID: 26808342.

4. Sharma SV, Bell DW, Settleman J, Haber DA. Epidermal growth factor receptor mutations in lung cancer. Nat Rev Cancer. 2007;7(3):169-81. PubMed PMID: 17318210.

5. Kosaka T, Yatabe Y, Endoh H, Kuwano H, Takahashi T, Mitsudomi T. Mutations of the epidermal growth factor receptor gene in lung cancer: biological and clinical implications. Cancer Res. 2004;64(24):8919-23. PubMed PMID: 15604253.

6. Mendelsohn J, Baselga J. Status of epidermal growth factor receptor antagonists in the biology and treatment of cancer. J Clin Oncol. 2003;21(14):2787-99. PubMed PMID: 12860957. 
7. Jänne PA, Engelman JA, Johnson BE. Epidermal growth factor receptor mutations in non-small-cell lung cancer: implications for treatment and tumor biology. J Clin Oncol. 2005;23(14):3227-34. PubMed PMID: 15886310 .

8. Han S-W, Kim T-Y, Hwang PG, Jeong S, Kim J, Choi IS, et al. Predictive and prognostic impact of epidermal growth factor receptor mutation in non-small-cell lung cancer patients treated with gefitinib. $\mathrm{J}$ Clin Oncol. 2005;23(11):2493-501. PubMed PMID: 15710947.

9. Shi Y, Au JS-K, Thongprasert S, Srinivasan S, Tsai C-M, Khoa MT, et al. A prospective, molecular epidemiology study of EGFR mutations in Asian patients with advanced non-small-cell lung cancer of adenocarcinoma histology (PIONEER). J Thorac Oncol. 2014;9(2):154-62. doi: 10.1097/JTO.0000000000000033. PubMed PMID: 24419411.

10. Engelman JA, Jänne PA. Factors predicting response to EGFR tyrosine kinase inhibitors. Semin Respir Crit Care Med. 2005;26(3):314-22. PubMed PMID: 16052433.

11. Mok TS, Wu Y-L, Thongprasert S, Yang C-H, Chu D-T, Saijo N, et al. Gefitinib or carboplatin-paclitaxel in pulmonary adenocarcinoma. N Engl J Med. 2009;361(10):947-57. doi: 10.1056/NEJMoa0810699. PubMed PMID: 19692680.

12. Maemondo M, Inoue A, Kobayashi K, Sugawara S, Oizumi S, Isobe H, et al. Gefitinib or chemotherapy for non-small-cell lung cancer with mutated EGFR. N Engl J Med. 2010;362(25):2380-8. doi: 10.1056/NEJMoa0909530. PubMed PMID: 20573926.

13. Crinò L, Cappuzzo F, Zatloukal P, Reck M, Pesek M, Thompson JC, et al. Gefitinib versus vinorelbine in chemotherapy-naive elderly patients with advanced non-small-cell lung cancer (INVITE): a randomized, phase II study. J Clin Oncol. 2008;26(26):4253-60. doi: 10.1200/JCO.2007.15.0672. PubMed PMID: 18779612.

14. Sun J-M, Lee KH, Kim S-W, Lee DH, Min YJ, Yun HJ, et al. Gefitinib versus pemetrexed as second-line treatment in patients with nonsmall cell lung cancer previously treated with platinum-based chemotherapy (KCSG-LU08-01): an open-label, phase 3 trial. Cancer. 2012;118(24):6234-42. doi: 10.1002/cncr.27630. PubMed PMID: 22674612.

15. Mitsudomi T, Morita S, Yatabe Y, Negoro S, Okamoto I, Tsurutani J, et al. Gefitinib versus cisplatin plus docetaxel in patients with non-small-cell lung cancer harbouring mutations of the epidermal growth factor receptor (WJTOG3405): an open label, randomised phase 3 trial. Lancet Oncol. 2010;11(2):121-8. doi: 10.1016/S1470-2045(09)70364-X. PubMed PMID: 20022809.

16. Wu YL, Zhou C, Liam CK, Wu G, Liu X, Zhong Z, et al. First-line erlotinib versus gemcitabine/cisplatin in patients with advanced EGFR mutation-positive non-small-cell lung cancer: analyses from the phase III, randomized, open-label, ENSURE study. Ann Oncol. 2015;26(9):1883-9. doi: 10.1093/annonc/mdv270. PubMed PMID: 26105600.

17. Zhou C, Wu YL, Chen G, Feng J, Liu XQ, Wang C, et al. Final overall survival results from a randomised, phase III study of erlotinib versus chemotherapy as first-line treatment of EGFR mutation-positive advanced non-small-cell lung cancer (OPTIMAL, CTONG-0802). Ann Oncol. 2015;26(9):1877-83. doi: 10.1093/annonc/mdv276. PubMed PMID: 26141208.

18. Zhou C, Wu Y-L, Chen G, Feng J, Liu X-Q, Wang C, et al. Erlotinib versus chemotherapy as firstline treatment for patients with advanced EGFR mutation-positive non-small-cell lung cancer (OPTIMAL, CTONG-0802): a multicentre, open-label, randomised, phase 3 study. Lancet Oncol. 2011;12(8):735-42. doi: 10.1016/S1470-2045(11)70184-X. PubMed PMID: 21783417.

19. Karampeazis A, Voutsina A, Souglakos J, Kentepozidis N, Giassas S, Christofillakis C, et al. Pemetrexed versus erlotinib in pretreated patients with advanced non-small cell lung cancer: a Hellenic Oncology Research Group (HORG) randomized phase 3 study. Cancer. 2013;119(15):2754-64. doi: 10.1002/cncr.28132. PubMed PMID: 23661337. 
20. Wu YL, Zhou C, Cheng Y, Lu S, Chen GY, Huang C, et al. Erlotinib as second-line treatment in patients with advanced non-small-cell lung cancer and asymptomatic brain metastases: a phase II study (CTONG-0803). Ann Oncol. 2013;24(4):993-9. doi: 10.1093/annonc/mds529. PubMed PMID: 23129122.

21. Rosell R, Carcereny E, Gervais R, Vergnenegre A, Massuti B, Felip E, et al. Erlotinib versus standard chemotherapy as first-line treatment for European patients with advanced EGFR mutation-positive non-small-cell lung cancer (EURTAC): a multicentre, open-label, randomised phase 3 trial. Lancet Oncol. 2012;13(3):239-46. doi: 10.1016/S1470-2045(11)70393-X. PubMed PMID: 22285168.

22. Schuler M, Wu Y-L, Hirsh V, O'Byrne K, Yamamoto N, Mok T, et al. First-Line Afatinib versus Chemotherapy in Patients with Non-Small Cell Lung Cancer and Common Epidermal Growth Factor Receptor Gene Mutations and Brain Metastases. J Thorac Oncol. 2016;11(3):380-90. doi: 10.1016/j.jtho.2015.11.014. PubMed PMID: 26823294.

23. Wu Y-L, Zhou C, Hu C-P, Feng J, Lu S, Huang Y, et al. Afatinib versus cisplatin plus gemcitabine for first-line treatment of Asian patients with advanced non-small-cell lung cancer harbouring EGFR mutations (LUX-Lung 6): an open-label, randomised phase 3 trial. Lancet Oncol. 2014;15(2):213-22. doi: 10.1016/S14702045(13)70604-1. PubMed PMID: 24439929.

24. Sequist LV, Yang JC-H, Yamamoto N, O'Byrne K, Hirsh V, Mok T, et al. Phase III study of afatinib or cisplatin plus pemetrexed in patients with metastatic lung adenocarcinoma with EGFR mutations. J Clin Oncol. 2013;31(27):3327-34. doi: 10.1200/JCO.2012.44.2806. PubMed PMID: 23816960.

25. Kato T, Yoshioka H, Okamoto I, Yokoyama A, Hida T, Seto T, et al. Afatinib versus cisplatin plus pemetrexed in Japanese patients with advanced non-small cell lung cancer harboring activating EGFR mutations: Subgroup analysis of LUX-Lung 3. Cancer Sci. 2015;106(9):1202-11. doi: 10.1111/cas.12723. PubMed PMID: 26094656.

26. Wu Y-L, Cheng Y, Zhou X, Lee KH, Nakagawa K, Niho S, et al. Dacomitinib versus gefitinib as firstline treatment for patients with EGFR-mutation-positive non-small-cell lung cancer (ARCHER 1050): a randomised, open-label, phase 3 trial. Lancet Oncol. 2017;18(11):1454-66. doi: 10.1016/S1470-2045(17)306083. PubMed PMID: 28958502.

27. Mok TS, Cheng Y, Zhou X, Lee KH, Nakagawa K, Niho S, et al. Improvement in Overall Survival in a Randomized Study That Compared Dacomitinib With Gefitinib in Patients With Advanced Non-Small-Cell Lung Cancer and EGFR-Activating Mutations. J Clin Oncol. 2018;36(22):2244-50. doi: 10.1200/JCO.2018.78.7994. PubMed PMID: 29864379.

28. Soria J-C, Ohe Y, Vansteenkiste J, Reungwetwattana T, Chewaskulyong B, Lee KH, et al. Osimertinib in Untreated EGFR-Mutated Advanced Non-Small-Cell Lung Cancer. N Engl J Med. 2018;378(2):113-25. doi: 10.1056/NEJMoa1713137. PubMed PMID: 29151359.

29. Ramalingam SS, Vansteenkiste J, Planchard D, Cho BC, Gray JE, Ohe Y, et al. Overall Survival with Osimertinib in Untreated, -Mutated Advanced NSCLC. N Engl J Med. 2020;382(1):41-50. doi: 10.1056/NEJMoa1913662. PubMed PMID: 31751012.

30. Mok TS, Wu Y-L, Ahn M-J, Garassino MC, Kim HR, Ramalingam SS, et al. Osimertinib or PlatinumPemetrexed in EGFR T790M-Positive Lung Cancer. N Engl J Med. 2017;376(7):629-40. doi: 10.1056/NEJMoa1612674. PubMed PMID: 27959700.

31. Akamatsu H, Katakami N, Okamoto I, Kato T, Kim YH, Imamura F, et al. Osimertinib in Japanese patients with EGFR T790M mutation-positive advanced non-small-cell lung cancer: AURA3 trial. Cancer Sci. 2018;109(6):1930-8. doi: 10.1111/cas.13623. PubMed PMID: 29697876.

32. Wu Y-L, Ahn M-J, Garassino MC, Han J-Y, Katakami N, Kim HR, et al. CNS Efficacy of Osimertinib in Patients With T790M-Positive Advanced Non-Small-Cell Lung Cancer: Data From a Randomized Phase III Trial (AURA3). J Clin Oncol. 2018;36(26):2702-9. doi: 10.1200/JCO.2018.77.9363. PubMed PMID: 30059262. 
33. Nie K, Zhang Z, Zhang C, Geng C, Zhang L, Xu X, et al. Osimertinib compared docetaxel-bevacizumab as third-line treatment in EGFR T790M mutated non-small-cell lung cancer. Lung Cancer. 2018;121. doi: 10.1016/j.lungcan.2018.04.012. PubMed PMID: 29858027.

34. Pao W, Miller VA, Politi KA, Riely GJ, Somwar R, Zakowski MF, et al. Acquired resistance of lung adenocarcinomas to gefitinib or erlotinib is associated with a second mutation in the EGFR kinase domain. PLoS Med. 2005;2(3):e73. PubMed PMID: 15737014.

35. Sequist LV, Waltman BA, Dias-Santagata D, Digumarthy S, Turke AB, Fidias P, et al. Genotypic and histological evolution of lung cancers acquiring resistance to EGFR inhibitors. Sci Transl Med. 2011;3(75):75ra26. doi: 10.1126/scitranslmed.3002003. PubMed PMID: 21430269.

36. Yu HA, Arcila ME, Rekhtman N, Sima CS, Zakowski MF, Pao W, et al. Analysis of tumor specimens at the time of acquired resistance to EGFR-TKI therapy in 155 patients with EGFR-mutant lung cancers. Clin Cancer Res. 2013;19(8):2240-7. doi: 10.1158/1078-0432.CCR-12-2246. PubMed PMID: 23470965.

37. Thress KS, Paweletz CP, Felip E, Cho BC, Stetson D, Dougherty B, et al. Acquired EGFR C797S mutation mediates resistance to AZD9291 in non-small cell lung cancer harboring EGFR T790M. Nat Med. 2015;21(6):560-2. doi: 10.1038/nm.3854. PubMed PMID: 25939061.

38. Jia Y, Yun C-H, Park E, Ercan D, Manuia M, Juarez J, et al. Overcoming EGFR(T790M) and EGFR(C797S) resistance with mutant-selective allosteric inhibitors. Nature. 2016;534(7605):129-32. doi: 10.1038/nature17960. PubMed PMID: 27251290.

39. Zhang Q, Zhang X-C, Yang J-J, Yang Z-F, Bai Y, Su J, et al. EGFR L792H and G796R: Two Novel Mutations Mediating Resistance to the Third-Generation EGFR Tyrosine Kinase Inhibitor Osimertinib. J Thorac Oncol. 2018;13(9):1415-21. doi: 10.1016/j.jtho.2018.05.024. PubMed PMID: 29857056.

40. Hanahan D, Coussens LM. Accessories to the crime: functions of cells recruited to the tumor microenvironment. Cancer Cell. 2012;21(3):309-22. doi: 10.1016/j.ccr.2012.02.022. PubMed PMID: 22439926.

41. Quail DF, Joyce JA. Microenvironmental regulation of tumor progression and metastasis. Nat Med. 2013;19(11):1423-37. doi: 10.1038/nm.3394. PubMed PMID: 24202395.

42. Frantz C, Stewart KM, Weaver VM. The extracellular matrix at a glance. J Cell Sci. 2010;123(Pt 24):4195-200. doi: 10.1242/jcs.023820. PubMed PMID: 21123617.

43. Lo H-W, Hsu S-C, Xia W, Cao X, Shih J-Y, Wei Y, et al. Epidermal growth factor receptor cooperates with signal transducer and activator of transcription 3 to induce epithelial-mesenchymal transition in cancer cells via up-regulation of TWIST gene expression. Cancer Res. 2007;67(19):9066-76. PubMed PMID: 17909010.

44. Hugo HJ, Wafai R, Blick T, Thompson EW, Newgreen DF. Staurosporine augments EGF-mediated EMT in PMC42-LA cells through actin depolymerisation, focal contact size reduction and Snail1 induction - a model for cross-modulation. BMC Cancer. 2009;9:235. doi: 10.1186/1471-2407-9-235. PubMed PMID: 19604397.

45. Zuo J-H, Zhu W, Li M-Y, Li X-H, Yi H, Zeng G-Q, et al. Activation of EGFR promotes squamous carcinoma SCC10A cell migration and invasion via inducing EMT-like phenotype change and MMP-9-mediated degradation of E-cadherin. J Cell Biochem. 2011;112(9):2508-17. doi: 10.1002/jcb.23175. PubMed PMID: 21557297.

46. Zuo J, Wen M, Li S, Lv X, Wang L, Ai X, et al. Overexpression of CXCR4 promotes invasion and migration of non-small cell lung cancer via EGFR and MMP-9. Oncol Lett. 2017;14(6):7513-21. doi: 10.3892/ol.2017.7168. PubMed PMID: 29344197.

47. Wang Y, Zhang T, Guo L, Ren T, Yang Y. Stromal extracellular matrix is a microenvironmental cue promoting resistance to EGFR tyrosine kinase inhibitors in lung cancer cells. Int J Biochem Cell Biol. 
2019;106. doi: 10.1016/j.biocel.2018.11.001. PubMed PMID: 30471423.

48. Kalluri R, Zeisberg M. Fibroblasts in cancer. Nat Rev Cancer. 2006;6(5):392-401. PubMed PMID: 16572188 .

49. Yi Y, Zeng S, Wang Z, Wu M, Ma Y, Ye X, et al. Cancer-associated fibroblasts promote epithelialmesenchymal transition and EGFR-TKI resistance of non-small cell lung cancers via HGF/IGF-1/ANXA2 signaling. Biochim Biophys Acta Mol Basis Dis. 2018;1864(3):793-803. doi: 10.1016/j.bbadis.2017.12.021. PubMed PMID: 29253515.

50. Ishibashi M, Neri S, Hashimoto H, Miyashita T, Yoshida T, Nakamura Y, et al. CD200-positive cancer associated fibroblasts augment the sensitivity of Epidermal Growth Factor Receptor mutation-positive lung adenocarcinomas to EGFR Tyrosine kinase inhibitors. Sci Rep. 2017;7:46662. doi: 10.1038/srep46662. PubMed PMID: 28429795.

51. Yoshida T, Ishii G, Goto K, Neri S, Hashimoto H, Yoh K, et al. Podoplanin-positive cancer-associated fibroblasts in the tumor microenvironment induce primary resistance to EGFR-TKIs in lung adenocarcinoma with EGFR mutation. Clin Cancer Res. 2015;21(3):642-51. doi: 10.1158/1078-0432.CCR-14-0846. PubMed PMID: 25388165.

52. Arena S, Salati M, Sorgentoni G, Barbisan F, Orciani M. Characterization of tumor-derived mesenchymal stem cells potentially differentiating into cancer-associated fibroblasts in lung cancer. Clin Transl Oncol. 2018;20(12):1582-91. doi: 10.1007/s12094-018-1894-4. PubMed PMID: 29796998.

53. Carmeliet P. Angiogenesis in health and disease. Nat Med. 2003;9(6):653-60. PubMed PMID: 12778163.

54. Pugh CW, Ratcliffe PJ. Regulation of angiogenesis by hypoxia: role of the HIF system. Nat Med. 2003;9(6):677-84. PubMed PMID: 12778166.

55. Ferrara N, Gerber H-P, LeCouter J. The biology of VEGF and its receptors. Nat Med. 2003;9(6):669-76. PubMed PMID: 12778165.

56. Togashi Y, Masago K, Kubo T, Fujimoto D, Sakamori Y, Nagai H, et al. Association between vascularpoor area of primary tumors and epidermal growth factor receptor gene status in advanced lung adenocarcinoma. Med Oncol. 2012;29(5):3169-75. doi: 10.1007/s12032-012-0235-7. PubMed PMID: 22492281.

57. Yuan X-H, Yang J, Wang X-Y, Zhang X-L, Qin T-T, Li K. Association between EGFR/KRAS mutation and expression of VEGFA, VEGFR and VEGFR2 in lung adenocarcinoma. Oncol Lett. 2018;16(2):2105-12. doi: 10.3892/ol.2018.8901. PubMed PMID: 30008907.

58. Koizumi H, Yamada T, Takeuchi S, Nakagawa T, Kita K, Nakamura T, et al. Hsp90 inhibition overcomes HGF-triggering resistance to EGFR-TKIs in EGFR-mutant lung cancer by decreasing client protein expression and angiogenesis. J Thorac Oncol. 2012;7(7):1078-85. doi: 10.1097/JTO.0b013e3182519a2c. PubMed PMID: 22592212.

59. Nakade J, Takeuchi S, Nakagawa T, Ishikawa D, Sano T, Nanjo S, et al. Triple inhibition of EGFR, Met, and VEGF suppresses regrowth of HGF-triggered, erlotinib-resistant lung cancer harboring an EGFR mutation. J Thorac Oncol. 2014;9(6):775-83. doi: 10.1097/JTO.0000000000000170. PubMed PMID: 24828661.

60. Lee JG, Wu R. Erlotinib-cisplatin combination inhibits growth and angiogenesis through c-MYC and HIF-1 $\alpha$ in EGFR-mutated lung cancer in vitro and in vivo. Neoplasia. 2015;17(2):190-200. doi: 10.1016/j.neo.2014.12.008. PubMed PMID: 25748238.

61. Mantovani A, Allavena P, Sica A, Balkwill F. Cancer-related inflammation. Nature. 2008;454(7203):43644. doi: 10.1038/nature07205. PubMed PMID: 18650914.

62. Shapouri-Moghaddam A, Mohammadian S, Vazini H, Taghadosi M, Esmaeili S-A, Mardani F, et al. Macrophage plasticity, polarization, and function in health and disease. J Cell Physiol. 2018;233(9):6425-40. doi: 10.1002/jcp.26429. PubMed PMID: 29319160. 
63. Li Z, Maeda D, Yoshida M, Umakoshi M, Nanjo H, Shiraishi K, et al. The intratumoral distribution influences the prognostic impact of CD68- and CD204-positive macrophages in non-small cell lung cancer. Lung Cancer. 2018;123:127-35. doi: 10.1016/j.lungcan.2018.07.015. PubMed PMID: 30089583.

64. Saruwatari K, Ikemura S, Sekihara K, Kuwata T, Fujii S, Umemura S, et al. Aggressive tumor microenvironment of solid predominant lung adenocarcinoma subtype harboring with epidermal growth factor receptor mutations. Lung Cancer. 2016;91. doi: 10.1016/j.lungcan.2015.11.012. PubMed PMID: 26711928.

65. Feng P-H, Yu C-T, Chen K-Y, Luo C-S, Wu SM, Liu C-Y, et al. S100A9 MDSC and TAM-mediated EGFR-TKI resistance in lung adenocarcinoma: the role of RELB. Oncotarget. 2018;9(7):7631-43. doi: 10.18632/oncotarget.24146. PubMed PMID: 29484139.

66. Qian B-Z, Pollard JW. Macrophage diversity enhances tumor progression and metastasis. Cell. 2010;141(1):39-51. doi: 10.1016/j.cell.2010.03.014. PubMed PMID: 20371344.

67. Zhang B, Zhang Y, Zhao J, Wang Z, Wu T, Ou W, et al. M2-polarized macrophages contribute to the decreased sensitivity of EGFR-TKIs treatment in patients with advanced lung adenocarcinoma. Med Oncol. 2014;31(8):127. doi: 10.1007/s12032-014-0127-0. PubMed PMID: 25034365.

68. Waisman A, Lukas D, Clausen BE, Yogev N. Dendritic cells as gatekeepers of tolerance. Semin Immunopathol. 2017;39(2):153-63. doi: 10.1007/s00281-016-0583-z. PubMed PMID: 27456849.

69. Venugopalan A, Lee M-J, Niu G, Medina-Echeverz J, Tomita Y, Lizak MJ, et al. EGFR-targeted therapy results in dramatic early lung tumor regression accompanied by imaging response and immune infiltration in EGFR mutant transgenic mouse models. Oncotarget. 2016;7(34):54137-56. doi: 10.18632/oncotarget.11021. PubMed PMID: 27494838.

70. Yu S, Sha H, Qin X, Chen Y, Li X, Shi M, et al. EGFR E746-A750 deletion in lung cancer represses antitumor immunity through the exosome-mediated inhibition of dendritic cells. Oncogene. 2020;39(13):2643-57. doi: 10.1038/s41388-020-1182-y. PubMed PMID: 32001818.

71. Nigro A, Ricciardi L, Salvato I, Sabbatino F, Vitale M, Crescenzi MA, et al. Enhanced Expression of CD47 Is Associated With Off-Target Resistance to Tyrosine Kinase Inhibitor Gefitinib in NSCLC. Front Immunol. 2019;10:3135. doi: 10.3389/fimmu.2019.03135. PubMed PMID: 32082304.

72. Waldhauer I, Steinle A. NK cells and cancer immunosurveillance. Oncogene. 2008;27(45):5932-43. doi: 10.1038/onc.2008.267. PubMed PMID: 18836474.

73. Tu C, Zhu Y, Jiang B, He W, Jin C. Correlation between circulating tumor cells EGFR expression and $\mathrm{T}$ cell subsets in advanced non-small cell lung cancer patients after tyrosine kinase inhibitor treatment. Neoplasma. 2017;64(4):619-25. doi: 10.4149/neo_2017_418. PubMed PMID: 28485170.

74. Park H-R, Ahn Y-O, Kim TM, Kim S, Kim S, Lee YS, et al. NK92-CD16 cells are cytotoxic to nonsmall cell lung cancer cell lines that have acquired resistance to tyrosine kinase inhibitors. Cytotherapy. 2019;21(6):603-11. doi: 10.1016/j.jcyt.2019.03.312. PubMed PMID: 31010733.

75. He S, Yin T, Li D, Gao X, Wan Y, Ma X, et al. Enhanced interaction between natural killer cells and lung cancer cells: involvement in gefitinib-mediated immunoregulation. J Transl Med. 2013;11:186. doi: 10.1186/1479-5876-11-186. PubMed PMID: 23937717.

76. Kumar V, Patel S, Tcyganov E, Gabrilovich DI. The Nature of Myeloid-Derived Suppressor Cells in the Tumor Microenvironment. Trends Immunol. 2016;37(3):208-20. doi: 10.1016/j.it.2016.01.004. PubMed PMID: 26858199.

77. Gabrilovich DI. Myeloid-Derived Suppressor Cells. Cancer Immunol Res. 2017;5(1):3-8. doi: 10.1158/2326-6066.CIR-16-0297. PubMed PMID: 28052991.

78. Feng P-H, Chen K-Y, Huang Y-C, Luo C-S, Wu SM, Chen T-T, et al. Bevacizumab Reduces S100A9Positive MDSCs Linked to Intracranial Control in Patients with EGFR-Mutant Lung Adenocarcinoma. J 
Thorac Oncol. 2018;13(7):958-67. doi: 10.1016/j.jtho.2018.03.032. PubMed PMID: 29684573.

79. Liew PX, Kubes P. The Neutrophil's Role During Health and Disease. Physiol Rev. 2019;99(2):1223-48. doi: 10.1152/physrev.00012.2018. PubMed PMID: 30758246.

80. Zhang Y, Feng Y-C, Zhu H-G, Xiong T-C, Hou Y-S, Song J, et al. The peripheral blood neutrophil-tolymphocyte ratio is a prognostic predictor for survival of EGFR-mutant nonsmall cell lung cancer patients treated with EGFR-TKIs. Medicine (Baltimore). 2018;97(30):e11648. doi: 10.1097/MD.0000000000011648. PubMed PMID: 30045314.

81. Meriggi F, Codignola C, Beretta GD, Ceresoli GL, Caprioli A, Scartozzi M, et al. Significance of neutrophil-to-lymphocyte ratio in Western advanced EGFR-mutated non-small cell lung cancer receiving a targeted therapy. Tumori. 2017;103(5):443-8. doi: 10.5301/tj.5000632. PubMed PMID: 28731495.

82. Lin G-N, Peng J-W, Liu P-P, Liu D-Y, Xiao J-J, Chen X-Q. Elevated neutrophil-to-lymphocyte ratio predicts poor outcome in patients with advanced non-small-cell lung cancer receiving first-line gefitinib or erlotinib treatment. Asia Pac J Clin Oncol. 2017;13(5):e189-e94. doi: 10.1111/ajco.12273. PubMed PMID: 25359280 .

83. Mansuet-Lupo A, Alifano M, Pécuchet N, Biton J, Becht E, Goc J, et al. Intratumoral Immune Cell Densities Are Associated with Lung Adenocarcinoma Gene Alterations. Am J Respir Crit Care Med. 2016;194(11):1403-12. PubMed PMID: 27299180.

84. Franchina DG, Grusdat M, Brenner D. B-Cell Metabolic Remodeling and Cancer. Trends Cancer. 2018;4(2):138-50. doi: 10.1016/j.trecan.2017.12.006. PubMed PMID: 29458963.

85. Wang C, Yin R, Dai J, Gu Y, Cui S, Ma H, et al. Whole-genome sequencing reveals genomic signatures associated with the inflammatory microenvironments in Chinese NSCLC patients. Nat Commun. 2018;9(1):2054. doi: 10.1038/s41467-018-04492-2. PubMed PMID: 29799009.

86. Germain C, Gnjatic S, Tamzalit F, Knockaert S, Remark R, Goc J, et al. Presence of B cells in tertiary lymphoid structures is associated with a protective immunity in patients with lung cancer. Am J Respir Crit Care Med. 2014;189(7):832-44. doi: 10.1164/rccm.201309-1611OC. PubMed PMID: 24484236.

87. Lohr M, Edlund K, Botling J, Hammad S, Hellwig B, Othman A, et al. The prognostic relevance of tumour-infiltrating plasma cells and immunoglobulin kappa $\mathrm{C}$ indicates an important role of the humoral immune response in non-small cell lung cancer. Cancer Lett. 2013;333(2):222-8. doi: 10.1016/j.canlet.2013.01.036. PubMed PMID: 23370224.

88. Bruno TC, Ebner PJ, Moore BL, Squalls OG, Waugh KA, Eruslanov EB, et al. Antigen-Presenting Intratumoral B Cells Affect CD4 TIL Phenotypes in Non-Small Cell Lung Cancer Patients. Cancer Immunol Res. 2017;5(10):898-907. doi: 10.1158/2326-6066.CIR-17-0075. PubMed PMID: 28848053.

89. Cai X, Zhang L, Wei W. Regulatory B cells in inflammatory diseases and tumor. Int Immunopharmacol. 2019;67:281-6. doi: 10.1016/j.intimp.2018.12.007. PubMed PMID: 30572252.

90. Zhang Y, Gallastegui N, Rosenblatt JD. Regulatory B cells in anti-tumor immunity. Int Immunol. 2015;27(10):521-30. doi: 10.1093/intimm/dxv034. PubMed PMID: 25999597.

91. Kumar BV, Connors TJ, Farber DL. Human T Cell Development, Localization, and Function throughout Life. Immunity. 2018;48(2):202-13. doi: 10.1016/j.immuni.2018.01.007. PubMed PMID: 29466753.

92. Zhang X-C, Wang J, Shao G-G, Wang Q, Qu X, Wang B, et al. Comprehensive genomic and immunological characterization of Chinese non-small cell lung cancer patients. Nat Commun. 2019;10(1):1772. doi: 10.1038/s41467-019-09762-1. PubMed PMID: 30992440.

93. Simoni Y, Becht E, Fehlings M, Loh CY, Koo S-L, Teng KWW, et al. Bystander CD8 T cells are abundant and phenotypically distinct in human tumour infiltrates. Nature. 2018;557(7706):575-9. doi: 10.1038/s41586018-0130-2. PubMed PMID: 29769722. 
94. Biton J, Mansuet-Lupo A, Pecuchet N, Alifano M, Ouakrim H, Arrondeau J, et al. TP53, STK11, and EGFR Mutations Predict Tumor Immune Profile and the Response to Anti-PD-1 in Lung Adenocarcinoma. Clin Cancer Res. 2018;24(22):5710-23. Epub 2018/05/17. doi: 10.1158/1078-0432.CCR-18-0163. PubMed PMID: 29764856.

95. Dong Z-Y, Zhang J-T, Liu S-Y, Su J, Zhang C, Xie Z, et al. EGFR mutation correlates with uninflamed phenotype and weak immunogenicity, causing impaired response to PD-1 blockade in non-small cell lung cancer. Oncoimmunology. 2017;6(11):e1356145. doi: 10.1080/2162402X.2017.1356145. PubMed PMID: 29147605.

96. Mazzaschi G, Madeddu D, Falco A, Bocchialini G, Goldoni M, Sogni F, et al. Low PD-1 Expression in Cytotoxic CD8 Tumor-Infiltrating Lymphocytes Confers an Immune-Privileged Tissue Microenvironment in NSCLC with a Prognostic and Predictive Value. Clin Cancer Res. 2018;24(2):407-19. doi: 10.1158/10780432.CCR-17-2156. PubMed PMID: 29074606.

97. Busch SE, Hanke ML, Kargl J, Metz HE, MacPherson D, Houghton AM. Lung Cancer Subtypes Generate Unique Immune Responses. J Immunol. 2016;197(11):4493-503. PubMed PMID: 27799309.

98. Datar I, Sanmamed MF, Wang J, Henick BS, Choi J, Badri T, et al. Expression Analysis and Significance of PD-1, LAG-3, and TIM-3 in Human Non-Small Cell Lung Cancer Using Spatially Resolved and Multiparametric Single-Cell Analysis. Clin Cancer Res. 2019;25(15):4663-73. doi: 10.1158/1078-0432.CCR-18-4142. PubMed PMID: 31053602.

99. Chen N, Fang W, Zhan J, Hong S, Tang Y, Kang S, et al. Upregulation of PD-L1 by EGFR Activation Mediates the Immune Escape in EGFR-Driven NSCLC: Implication for Optional Immune Targeted Therapy for NSCLC Patients with EGFR Mutation. J Thorac Oncol. 2015;10(6):910-23. doi: 10.1097/JTO.0000000000000500. PubMed PMID: 25658629.

100. Sugiyama E, Togashi Y, Takeuchi Y, Shinya S, Tada Y, Kataoka K, et al. Blockade of EGFR improves responsiveness to PD-1 blockade in -mutated non-small cell lung cancer. Sci Immunol. 2020;5(43). doi: 10.1126/sciimmunol.aav3937. PubMed PMID: 32005679.

101. Watanabe S, Hayashi H, Haratani K, Shimizu S, Tanizaki J, Sakai K, et al. Mutational activation of the epidermal growth factor receptor down-regulates major histocompatibility complex class I expression via the extracellular signal-regulated kinase in non-small cell lung cancer. Cancer Sci. 2019;110(1):52-60. doi: 10.1111/cas.13860. PubMed PMID: 30390416.

102. Shimizu K, Okita R, Saisho S, Maeda A, Nojima Y, Nakata M. Prognostic value of Cox-2 and PD-L1 expression and its relationship with tumor-infiltrating lymphocytes in resected lung adenocarcinoma. Cancer Manag Res. 2017;9:741-50. doi: 10.2147/CMAR.S146897. PubMed PMID: 29238224.

103. Liu S-Y, Dong Z-Y, Wu S-P, Xie Z, Yan L-X, Li Y-F, et al. Clinical relevance of PD-L1 expression and CD8+ T cells infiltration in patients with EGFR-mutated and ALK-rearranged lung cancer. Lung Cancer. 2018;125:86-92. doi: 10.1016/j.lungcan.2018.09.010. PubMed PMID: 30429043.

104. Haratani K, Hayashi H, Tanaka T, Kaneda H, Togashi Y, Sakai K, et al. Tumor immune microenvironment and nivolumab efficacy in EGFR mutation-positive non-small-cell lung cancer based on T790M status after disease progression during EGFR-TKI treatment. Ann Oncol. 2017;28(7):1532-9. doi: 10.1093/annonc/mdx183. PubMed PMID: 28407039.

105. Meniawy TM, Lake RA, McDonnell AM, Millward MJ, Nowak AK. PD-L1 on peripheral blood T lymphocytes is prognostic in patients with non-small cell lung cancer (NSCLC) treated with EGFR inhibitors. Lung Cancer. 2016;93. doi: 10.1016/j.lungcan.2015.12.006. PubMed PMID: 26898608.

106. Chen K, Cheng G, Zhang F, Zhu G, Xu Y, Yu X, et al. PD-L1 expression and T cells infiltration in patients with uncommon EGFR-mutant non-small cell lung cancer and the response to immunotherapy. Lung Cancer. 2020;142. doi: 10.1016/j.lungcan.2020.02.010. PubMed PMID: 32120230. 
107. Waldmann TA. Cytokines in Cancer Immunotherapy. Cold Spring Harb Perspect Biol. 2018;10(12). doi: 10.1101/cshperspect.a028472. PubMed PMID: 29101107.

108. Wang D-H, Lee H-S, Yoon D, Berry G, Wheeler TM, Sugarbaker DJ, et al. Progression of EGFRMutant Lung Adenocarcinoma is Driven By Alveolar Macrophages. Clin Cancer Res. 2017;23(3):778-88. doi: 10.1158/1078-0432.CCR-15-2597. PubMed PMID: 27496865.

109. Jiang X-M, Xu Y-L, Huang M-Y, Zhang L-L, Su M-X, Chen X, et al. Osimertinib (AZD9291) decreases programmed death ligand-1 in EGFR-mutated non-small cell lung cancer cells. Acta Pharmacol Sin. 2017;38(11):1512-20. doi: 10.1038/aps.2017.123. PubMed PMID: 28880013.

110. Wang S, Zhang Y, Wang Y, Ye P, Li J, Li H, et al. Amphiregulin Confers Regulatory T Cell Suppressive Function and Tumor Invasion via the EGFR/GSK-3ß/Foxp3 Axis. J Biol Chem. 2016;291(40):21085-95. PubMed PMID: 27432879.

111. Tsukita Y, Fujino N, Miyauchi E, Saito R, Fujishima F, Itakura K, et al. Axl kinase drives immune checkpoint and chemokine signalling pathways in lung adenocarcinomas. Mol Cancer. 2019;18(1):24. doi: 10.1186/s12943-019-0953-y. PubMed PMID: 30744655.

112. Joseph NA, Chiou S-H, Lung Z, Yang C-L, Lin T-Y, Chang H-W, et al. The role of HGF-MET pathway and CCDC66 cirRNA expression in EGFR resistance and epithelial-to-mesenchymal transition of lung adenocarcinoma cells. J Hematol Oncol. 2018;11(1):74. doi: 10.1186/s13045-018-0557-9. PubMed PMID: 29855336.

113. Yano S, Yamada T, Takeuchi S, Tachibana K, Minami Y, Yatabe Y, et al. Hepatocyte growth factor expression in EGFR mutant lung cancer with intrinsic and acquired resistance to tyrosine kinase inhibitors in a Japanese cohort. J Thorac Oncol. 2011;6(12):2011-7. doi: 10.1097/JTO.0b013e31823ab0dd. PubMed PMID: 22052230.

114. Yamada T, Takeuchi S, Kita K, Bando H, Nakamura T, Matsumoto K, et al. Hepatocyte growth factor induces resistance to anti-epidermal growth factor receptor antibody in lung cancer. J Thorac Oncol. 2012;7(2):272-80. doi: 10.1097/JTO.0b013e3182398e69. PubMed PMID: 22089117.

115. Yamada T, Matsumoto K, Wang W, Li Q, Nishioka Y, Sekido Y, et al. Hepatocyte growth factor reduces susceptibility to an irreversible epidermal growth factor receptor inhibitor in EGFR-T790M mutant lung cancer. Clin Cancer Res. 2010;16(1):174-83. doi: 10.1158/1078-0432.CCR-09-1204. PubMed PMID: 20008840 .

116. Han J-Y, Kim JY, Lee SH, Yoo NJ, Choi BG. Association between plasma hepatocyte growth factor and gefitinib resistance in patients with advanced non-small cell lung cancer. Lung Cancer. 2011;74(2):293-9. doi: 10.1016/j.lungcan.2011.02.021. PubMed PMID: 21440951.

117. Yano S, Wang W, Li Q, Matsumoto K, Sakurama H, Nakamura T, et al. Hepatocyte growth factor induces gefitinib resistance of lung adenocarcinoma with epidermal growth factor receptor-activating mutations. Cancer Res. 2008;68(22):9479-87. doi: 10.1158/0008-5472.CAN-08-1643. PubMed PMID: 19010923.

118. Gusenbauer S, Vlaicu P, Ullrich A. HGF induces novel EGFR functions involved in resistance formation to tyrosine kinase inhibitors. Oncogene. 2013;32(33):3846-56. doi: 10.1038/onc.2012.396. PubMed PMID: 23045285.

119. Tanaka H, Kimura T, Kudoh S, Mitsuoka S, Watanabe T, Suzumura T, et al. Reaction of plasma hepatocyte growth factor levels in non-small cell lung cancer patients treated with EGFR-TKIs. Int J Cancer. 2011;129(6):1410-6. doi: 10.1002/ijc.25799. PubMed PMID: 21128242.

120. Kasahara K, Arao T, Sakai K, Matsumoto K, Sakai A, Kimura H, et al. Impact of serum hepatocyte growth factor on treatment response to epidermal growth factor receptor tyrosine kinase inhibitors in patients with non-small cell lung adenocarcinoma. Clin Cancer Res. 2010;16(18):4616-24. doi: 10.1158/10780432.CCR-10-0383. PubMed PMID: 20679350. 
121. Jiao D, Chen J, Li Y, Tang X, Wang J, Xu W, et al. miR-1-3p and miR-206 sensitizes HGF-induced gefitinib-resistant human lung cancer cells through inhibition of c-Met signalling and EMT. J Cell Mol Med. 2018;22(7):3526-36. doi: 10.1111/jcmm.13629. PubMed PMID: 29664235.

122. Zhang Y, Zeng Y, Liu T, Du W, Zhu J, Liu Z, et al. The canonical TGF- $\beta$ /Smad signalling pathway is involved in PD-L1-induced primary resistance to EGFR-TKIs in EGFR-mutant non-small-cell lung cancer. Respir Res. 2019;20(1):164. doi: 10.1186/s12931-019-1137-4. PubMed PMID: 31331328.

123. Zhang L, Li QX, Wu HL, Lu X, Yang M, Yu SY, et al. SNPs in the transforming growth factor- $\beta$ pathway as predictors of outcome in advanced lung adenocarcinoma with EGFR mutations treated with gefitinib. Ann Oncol. 2014;25(8):1584-90. doi: 10.1093/annonc/mdu172. PubMed PMID: 24928833.

124. Soucheray M, Capelletti M, Pulido I, Kuang Y, Paweletz CP, Becker JH, et al. Intratumoral Heterogeneity in EGFR-Mutant NSCLC Results in Divergent Resistance Mechanisms in Response to EGFR Tyrosine Kinase Inhibition. Cancer Res. 2015;75(20):4372-83. doi: 10.1158/0008-5472.CAN-15-0377. PubMed PMID: 26282169.

125. Zhu Q, Zhang Z, Lu C, Xu F, Mao W, Zhang K, et al. Gefitinib promotes CXCR4-dependent epithelial to mesenchymal transition via TGF- $\beta 1$ signaling pathway in lung cancer cells harboring EGFR mutation. Clin Transl Oncol. 2020. doi: 10.1007/s12094-019-02266-w. PubMed PMID: 31900845.

126. Abera MB, Kazanietz MG. Protein kinase $\mathrm{C} \alpha$ mediates erlotinib resistance in lung cancer cells. Mol Pharmacol. 2015;87(5):832-41. doi: 10.1124/mol.115.097725. PubMed PMID: 25724832.

127. Shen H, Guan D, Shen J, Wang M, Chen X, Xu T, et al. TGF- $\beta 1$ induces erlotinib resistance in non-small cell lung cancer by down-regulating PTEN. Biomed Pharmacother. 2016;77:1-6. doi: 10.1016/j.biopha.2015.10.018. PubMed PMID: 26796257.

128. Izumchenko E, Chang X, Michailidi C, Kagohara L, Ravi R, Paz K, et al. The TGFß-miR200-MIG6 pathway orchestrates the EMT-associated kinase switch that induces resistance to EGFR inhibitors. Cancer Res. 2014;74(14):3995-4005. doi: 10.1158/0008-5472.CAN-14-0110. PubMed PMID: 24830724.

129. Tamura T, Kato Y, Ohashi K, Ninomiya K, Makimoto G, Gotoda H, et al. Potential influence of interleukin-6 on the therapeutic effect of gefitinib in patients with advanced non-small cell lung cancer harbouring EGFR mutations. Biochem Biophys Res Commun. 2018;495(1):360-7. doi: 10.1016/j.bbrc.2017.10.175. PubMed PMID: 29101033.

130. Nilsson MB, Sun H, Diao L, Tong P, Liu D, Li L, et al. Stress hormones promote EGFR inhibitor resistance in NSCLC: Implications for combinations with $\beta$-blockers. Sci Transl Med. 2017;9(415). doi: 10.1126/scitranslmed.aao4307. PubMed PMID: 29118262.

131. Jia Y, Li X, Zhao C, Jiang T, Zhao S, Zhang L, et al. Impact of serum vascular endothelial growth factor and interleukin- 6 on treatment response to epidermal growth factor receptor tyrosine kinase inhibitors in patients with non-small-cell lung cancer. Lung Cancer. 2018;125:22-8. doi: 10.1016/j.lungcan.2018.08.025. PubMed PMID: 30429024 .

132. Umeguchi H, Sueoka-Aragane N, Kobayashi N, Nakamura T, Sato A, Takeda Y, et al. Usefulness of plasma HGF level for monitoring acquired resistance to EGFR tyrosine kinase inhibitors in non-small cell lung cancer. Oncol Rep. 2015;33(1):391-6. doi: 10.3892/or.2014.3560. PubMed PMID: 25338771.

133. Cho JH, You Y-M, Yeom YI, Lee DC, Kim B-K, Won M, et al. RNF25 promotes gefitinib resistance in EGFR-mutant NSCLC cells by inducing NF- $x$ B-mediated ERK reactivation. Cell Death Dis. 2018;9(6):587. doi: 10.1038/s41419-018-0651-5. PubMed PMID: 29789542.

134. Ge P, Cao L, Chen X, Jing R, Yue W. miR-762 activation confers acquired resistance to gefitinib in non-small cell lung cancer. BMC Cancer. 2019;19(1):1203. doi: 10.1186/s12885-019-6416-4. PubMed PMID: 31823748 . 
135. Fernando RI, Hamilton DH, Dominguez C, David JM, McCampbell KK, Palena C. IL-8 signaling is involved in resistance of lung carcinoma cells to erlotinib. Oncotarget. 2016;7(27):42031-44. doi: 10.18632/oncotarget.9662. PubMed PMID: 27248176.

136. Karachaliou N, Cardona AF, Bracht JWP, Aldeguer E, Drozdowskyj A, Fernandez-Bruno M, et al. Integrin-linked kinase (ILK) and src homology 2 domain-containing phosphatase 2 (SHP2): Novel targets in EGFR-mutation positive non-small cell lung cancer (NSCLC). EBioMedicine. 2019;39:207-14. doi: 10.1016/j.ebiom.2018.11.036. PubMed PMID: 30473379.

137. Wang X, Zhang F, Yang X, Xue M, Li X, Gao Y, et al. Secreted Phosphoprotein 1 (SPP1) Contributes to Second-Generation EGFR Tyrosine Kinase Inhibitor Resistance in Non-Small Cell Lung Cancer. Oncol Res. 2019;27(8):871-7. doi: 10.3727/096504018X15426271404407. PubMed PMID: 30832751.

138. Zhou J, Wang J, Zeng Y, Zhang X, Hu Q, Zheng J, et al. Implication of epithelial-mesenchymal transition in IGF1R-induced resistance to EGFR-TKIs in advanced non-small cell lung cancer. Oncotarget. 2015;6(42):44332-45. doi: 10.18632/oncotarget.6293. PubMed PMID: 26554308.

139. Becker JH, Gao Y, Soucheray M, Pulido I, Kikuchi E, Rodríguez ML, et al. CXCR7 Reactivates ERK Signaling to Promote Resistance to EGFR Kinase Inhibitors in NSCLC. Cancer Res. 2019;79(17):4439-52. doi: 10.1158/0008-5472.CAN-19-0024. PubMed PMID: 31273063. 